\title{
Generic Bioaffinity Silicone Surfaces
}

Hong Chen,, ${ }^{\mathrm{a} b}$ Michael A. Brook, ${ }^{\mathrm{b}}$ Heather D. Sheardown, ${ }^{\mathrm{a}^{*}}$ Yang Chen, ${ }^{\mathrm{b}}$ and Bettina Klenkler $^{\mathrm{a}}$

${ }^{\mathrm{a}}$ Department of Chemical Engineering, ${ }^{\mathrm{b}}$ Department of Chemistry, McMaster University, 1280 Main St. W., Hamilton ON Canada, L8S 4M1

SUPPORTING MATERIAL 
Table S 1: Assignment of FT-IR spectra of succinimidyl carbonate PEG and modified surfaces

\begin{tabular}{|c|c|c|c|c|c|c|}
\hline \multirow[t]{2}{*}{ Peak } & \multicolumn{5}{|c|}{ Wavenumber $\left(\mathrm{cm}^{-1}\right)$} & \multirow[t]{2}{*}{ Assignment } \\
\hline & $\mathrm{H}-\mathrm{Si}$ & NSC- & NSC- & RGD & YIGSR & \\
\hline & surface & PEO & PEO & surface & surface & \\
\hline & 1 & 2 & surface & 4 & 5 & \\
\hline & & & 3 & & & \\
\hline 1 & 2966 & 2965 & 2961 & 2961 & 2961 & C-H stretch \\
\hline 2 & & 2868 & 2873 & 2874 & 2874 & Glycol $\mathrm{CH}_{2}$ stretch \\
\hline 3 & 2166 & - & - & - & - & Si-H stretch \\
\hline 4 & - & 1788 & 1789 & & & $\mathrm{C}=\mathrm{O}$ (on $\mathrm{O}-\mathrm{C}(\mathrm{O})-\mathrm{O}$ linkage) \\
\hline & & & & & & stretch \\
\hline 5 & - & 1740 & 1741 & - & - & $\mathrm{C}=\mathrm{O} \quad$ (on NHS group) \\
\hline & & & & & & stretch \\
\hline 6 & - & 1717 & 1715 & 1713 & 1713 & \\
\hline 7 & - & - & - & 1652 & 1656 & Amide I stretch \\
\hline 8 & & 1454 & 1456 & 1449 & 1453 & Glycol $\mathrm{CH}_{2}$ scissoring \\
\hline 9 & 1410 & 1410 & 1411 & 1411 & 1409 & \\
\hline 10 & & 1351 & 1351 & 1348 & 1350 & $\begin{array}{l}\text { Glycol }\left(\mathrm{OCH}_{2}-\mathrm{CH}_{2}\right) \text { chain } \\
\text { antisymmetric stretch }\end{array}$ \\
\hline
\end{tabular}

${ }^{\mathrm{a}}$ Refers to peak numbers in Figure 1. 


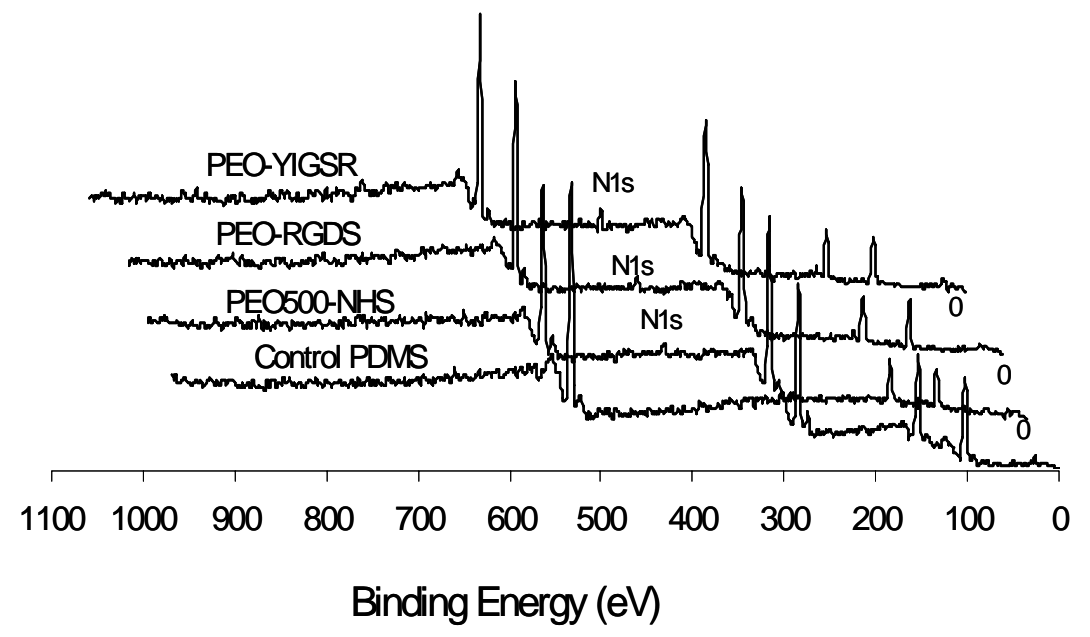

Fig. S 1: Survey XPS spectra: (a) unmodified PDMS; (b) succinimidyl carbonate PEG- 3, (c) RGDS-PEG 4, and, (d) YIGSR PEG modified-PDMS 5 surfaces. 